\title{
Supine versus Prone Miniaturised Percutaneous Nephrolithotomy in Elderly Patients
}

\author{
Murat Sahan ${ }^{1}$, Serkan Yarimoglu' ${ }^{1}$, Omer Sarilar ${ }^{2}$, Ufuk Caglar ${ }^{2}$ and Faruk Ozgor ${ }^{2}$ \\ ${ }^{1}$ Department of Urology, Bozyaka Teaching and Research Hospital, Izmir, Turkey \\ ${ }^{2}$ Department of Urology, Haseki Teaching and Research Hospital, Istanbul, Turkey
}

\begin{abstract}
Objective: To compare the outcomes of mini-PCNL (miniaturised percutaneous nephrolithotomy) in prone and supine positions in elderly patients.

Study Design: Cohort study.

Place and Duration of Study: Department of Urology, University of Health Sciences, Turkey, between April 2017 and January 2021.

Methodology: Patients over 65 years of age were included in the study. All patients' comorbidities were recorded and charlson comorbidity index $(\mathrm{CCl})$ score was calculated. The groups were compared in terms of perioperative values, stone-free rates and complication rates. Logistic regression analysis was used to evaluate risk factors for complication development. Postoperative complications were noted according to the Clavien scoring system (CSS).

Results: There were 54 patients in the supine mini-PCNL group and 64 in the prone mini-PCNL group. The median ages were 67 in the prone and 66 in the supine group. $\mathrm{CCl}$ scores were similar in both groups $(p=0.735)$. Stone-free and total complication rates were not statistically different in the groups $(p=0.994$ and $p=0.247$, respectively). However, grade $1-2$ complication rates were significantly higher in the prone group $(p=0.020)$. $\mathrm{CCl}$ score and stone size were significantly associated with the development of complications ( $p=0.018$ and $p=0.034$, respectively).

Conclusion: The present study is the first to compare the outcomes of mini-PCNL in prone and supine position in geriatric patients. Supine mini-PCNL is a potentially safer alternative treatment method for older patients with high CCl scores.
\end{abstract}

Key Words: Percutaneous nephrolithotomy, Supine position, Elderly, Mini-PCNI, CCI score.

How to cite this article: Sahan M, Yarimoglu S, Sarilar O, Caglar U, Ozgor F. Supine versus Prone Miniaturised Percutaneous Nephrolithotomy in Elderly Patients. J Coll Physicians Surg Pak 2022; 32(03):340-345.

\section{INTRODUCTION}

Percutaneous nephrolithotomy (PCNL) is the accepted standard treatment for moderate - large renal calculi, according to EAU guidelines. ${ }^{1}$ The reported success rates of PCNL in various studies are between $51 \%$ and $100 \%$, and reported complication rates reached $83 \% .{ }^{2}$ However, despite high stone-free rates for PCNL, some authors reported higher rates of complications caused by oversized instrument and tract size. ${ }^{3}$ Mini-PCNL was developed as a solution, resulting in lower complication rates through 14-22 French (Fr)-tract size. ${ }^{4}$

Usually, proneposition is used for PCNL, which allows manouverability for direct and convenient access to the collecting system. Prone position significantly reduces the risk of bleeding, because itallows clear access Brodel's avascular renal parenchyma.

Correspondence to: Dr. Murat Sahan, Department of Urology, Bozyaka Teaching and Research Hospital, Izmir, Turkey

E-mail: muratsahan87@hotmail.com

Received: October 24, 2021; Revised: December 21, 2021;

Accepted: December 29, 2021

DOI: https://doi.org/10.29271/jcpsp.2022.03.340
However, it may cause problems associated with circulatory and ventilatory, because of compression on the chest. Cervical spine injuries, tracheal compression, and ocular injury may occur during manipulation of the patient's position. The supine position has advantages, including less pressure in the renal pelvis due to the downward direction of the tract, both reducing the risk of liquid absorption, and allowing easier spontaneous cleaning of parts of the stone with gravitational drainage of fluid. In addition, this position facilitates simultaneous performance of PCNL and ureteroscopic (URS) procedures, as well as improved airway control in the patient. It also enables the surgeon to be seated during the operation. PCNL performed in the supine position provides a more appropriate operation process, especially for patients with pulmonary or cardiovascular disease. $^{5}$

There is currently no worldwide consensus over which technique is preferable; therefore, urologists' decisions must take into account the needs of geriatric patients, who have a tendency to bleed, and have low cardiopulmonary performance. Although many studies have researched the results of prone PCNL in geriatric cases; however, no study has evaluated the role of supine position on PCNL outcomes in elderly patients. 
The objective of this study was to investigate the outcomes of mini-PCNL comparing prone and supine positions in geriatric patients.

\section{METHODOLOGY}

The data of patients over 65 years of age, who underwent miniPCNL at Department of Urology, University of Health Sciences, Turkey, between 2017 and 2021, were retrospectively analysed. The study was approved by Ethical Board (Meeting Decision No. 2021/174). The researchers excluded patients with neuromuscular disease, renal anomalies, coagulopathy, skeletal deformity and having a solitary kidney. Demographic characteristics, perioperative and postoperative results of the patients were compared between the groups.

Stone size was recorded as the longest diameter of the stone (longitudinal or transverse). In multiple intrarenal stones, individual stone sizes were recorded and then the total size calculated. Perioperative data included operative and fluoroscopy time, time of hospitalisation, access localisation, and success and complication rates. Moreover, postoperative complications were classified according to the Clavien scoring system. Logistic regression analysis was used in the assessment of risk factors for the development of complications. Charlson comorbidity index $(\mathrm{CCl})$ score was measured for all patients.

A total of 118 patients were divided into two groups, according to surgical technique. After the urine culture was confirmed to be negative, they were taken to the operation room. All procedures were performed under general anesthesia. After placement of $5 \mathrm{~F}$ ureteral catheter with fluoroscopy aid in Galdakao-modified supine Valdivia position, for each patient, a single renal access to the appropriate calyx was obtained with 18gauge needle under ultrasound-assisted fluoroscopic guidance below the 12th rib. At the end of the procedure, supine miniPCNL was completed by checking the ureter under direct vision by semirigidURS for residualstone. Afterurethral catheter insertion, pads were placed under the patient to achieve prone position, in order to allow the appropriate puncture, under the guidance of fluoroscopy. Mini-PCNL was performed through a 16.5 Fr amplatz sheath. Stone fragmentation was accomplished using a 12 Fr nephroscope (Karl Storz, Tuttlingen, Germany) with Holmium Yag Laser (Sphinx, Lisa laser, USA). The surgeon decided whether to insert a J catheter and/or nephrostomy tube; no totally tubeless procedures were performed.

The operative time was calculated from the initial puncture for an access tract to the final placement of nephrostomy tube or J catheter. All PCNL interventions were performed by two same experienced surgeons. A non-contrast CT was performed in first postoperative month, and success was defined as a total stone clearance.

The statistical package for the social sciences version 25 (SPSS IBM Corp., Armonk, NY, USA) programme was used. Normality of distribution of the variables was checked by Shapiro-Wilk test. Mann-Whitney U-test was used for comparison of the vari- ables between the groups. Descriptive data were given as median (quartile 1-quartile 3) for continuousvariables. Categorical variables were grouped and compared using the $\chi 2$ test or Fisher's exact test. Logistic regression analysis was performed to evaluate the parameters that were predicted to be risk factors for the development of complications. The data were analysed at a $95 \%$ confidence level, and a $p$ value of less than 0.05 was accepted as statistically significant.

\section{RESULTS}

Fifty-four patients were treated with supine mini-PCNL, and 64 with prone mini-PCNL. The median ages were 67 (66-68) in prone group and 66 (65-67) in supine group. The two groups' preoperative characteristics (age, ASA score, body mass index (BMI), $\mathrm{CCl}$ score and gender) were similar ( $p>0.05)$. The two groups also had similar rates of stone opacity, localisations and size, hounsfield unit of stone values $(p=0.421, p=0.878, p=$ 0.266 and $p=0.636$, respectively, Tablel).

Mean operation times of the two groups were similar ( $p=$ 0.063). The median fluoroscopy time for supine mini-PCNL and prone mini-PCNL groups was $1.0(1.0-2.0)$ minutes and 2.0 $(2.0-3.0)$ minutes, respectively $(p<0.001)$. However, the prone mini-PCNL group recorded longer hospital stay ( $p<0.001)$. The success rate was $79.6 \%$ for the supine mini-PCNL group and $79.7 \%$ for the prone mini-PCNL group, and the results were statistically similar $(p=0.994)$.

Despite similar total complication rates between groups $(20.4 \%$ and $29.7 \%$, respectively, $p=0.247)$, minor complication rates were significantly higher in the prone mini-PCNL group (20.3\%) than in the supine mini-PCNL group (5.5\%) $(p=0.020$, Table II).

Clavien Grade 1 complications were observed in two patients in supine mini-PCNL group and eight patients in prone mini-PCNL group. One patient in supine mini-PCNL group and four patients in prone mini-PCNL group required transfusion (Clavien Grade 2 ), and in prone mini-PCNL group, fever requiring antibiotic replacement was detected in one patient in the postoperative period (Clavien Grade 2). Five patients in supine mini-PCNL group and three in prone mini-PCNL group required JJ stent insertion under anesthesia (Clavien Grade 3, Table II).

Binary logistic analysis was used to assess operation method, stone size, operation time and $\mathrm{CCl}$ score, which are predicted as risk factors for the development of complications. Stone size greater than $25 \mathrm{~mm}$ and $\mathrm{CCl}$ score $\geq 2$ were found statistically significant in terms of complication development $(p=0.034$ and $p=0.018$, respectively). Odds ratio was calculated as 2.616 (95\% Cl: 1.1-6.4, $p=0.034)$ for stone size and $2.954(95 \% \mathrm{Cl}$ : 1.2-7.3, $p=0.018$ ) for CCI score (Table III).

\section{DISCUSSION}

It is important to choose the most suitable method when treating kidneystones inelderly patients, dueto multiplecomorbidities. Minimally invasive treatment or observation may be an option when presence of serious comorbidities. However, high percentage of geriatric patients have rapid stone growth. ${ }^{6}$ 
Table I: Comparison of patient demographic data, preoperative findings and stone properties by groups.

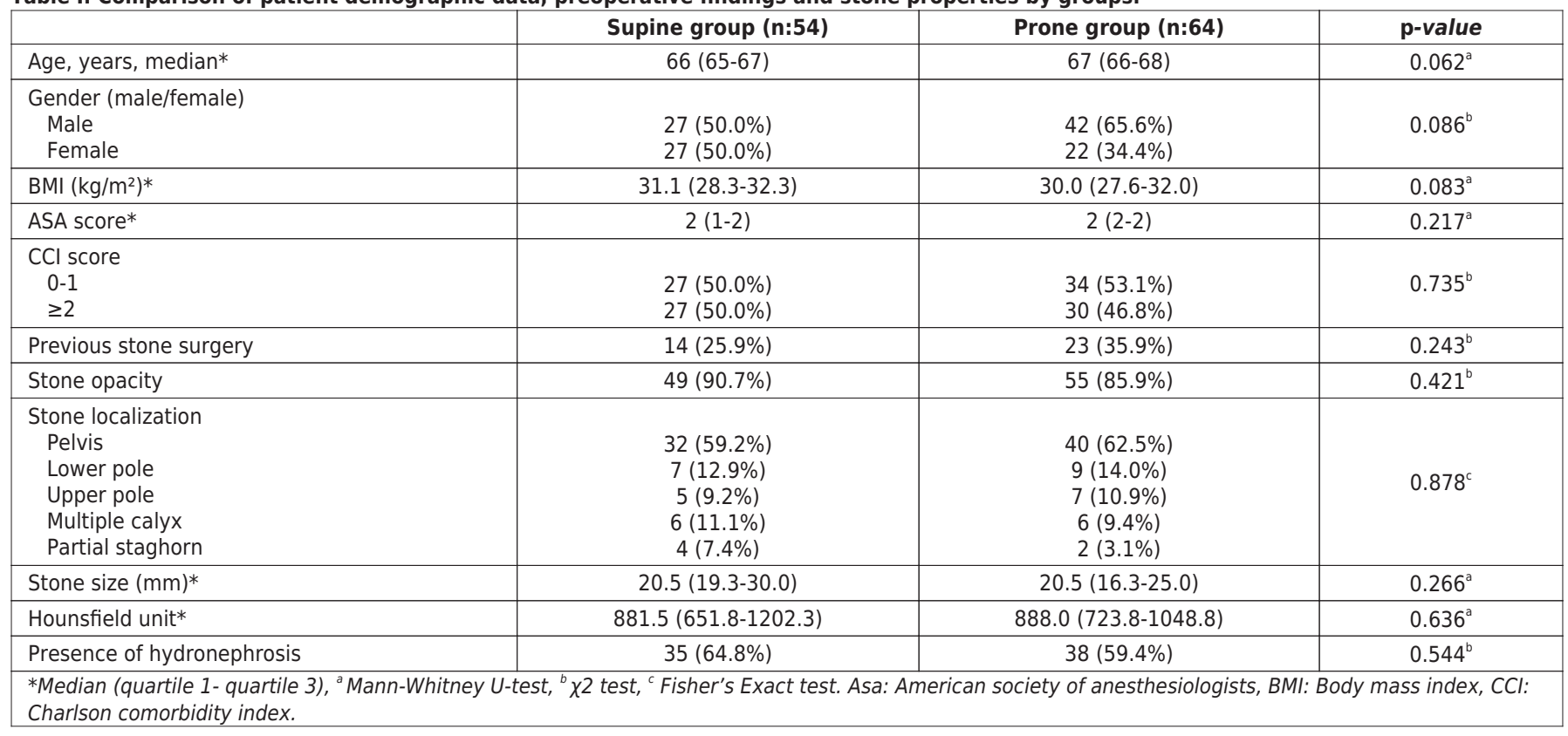

Table II: Comparison of operation data, postoperative follow-up results and complications between groups according to Clavien Dindo classification.

\begin{tabular}{|c|c|c|c|}
\hline & Supine group (n:54) & Prone group (n:64) & P-value \\
\hline Duration of operation $(\min )^{*}$ & $80.0(70.0-90.0)$ & $90.0(76.0-90.0)$ & $0.063^{\mathrm{a}}$ \\
\hline Duration of fluoroscopy (min)* & $1.0(1.0-2.0)$ & $2.0(2.0-3.0)$ & $<0.001^{a}$ \\
\hline $\begin{array}{l}\text { Side of operation } \\
\text { Right } \\
\text { Left }\end{array}$ & $\begin{array}{l}19(35.2 \%) \\
35(64.8 \%)\end{array}$ & $\begin{array}{l}26(40.6 \%) \\
38(59.4 \%)\end{array}$ & $0.544^{b}$ \\
\hline $\begin{array}{l}\text { Access localization } \\
\text { Lower calyx } \\
\text { Middle calyx } \\
\text { Upper calyx }\end{array}$ & $\begin{array}{c}35(64.8 \%) \\
16(29.6 \%) \\
3(5.5 \%)\end{array}$ & $\begin{array}{c}44(68.7 \%) \\
14(21.8 \%) \\
6(9.4 \%)\end{array}$ & $0.570^{c}$ \\
\hline $\begin{array}{l}\text { Number of Access } \\
1 \\
2 \\
3\end{array}$ & $\begin{array}{l}54(100.0 \%) \\
0(0 \%) \\
0(0 \%)\end{array}$ & $\begin{aligned} 58 & (90.6 \%) \\
5 & (7.8 \%) \\
1 & (1.6 \%)\end{aligned}$ & $0.062^{c}$ \\
\hline Intercostal access & $0(0 \%)$ & $3(4.6 \%)$ & $0.249^{c}$ \\
\hline Nephrostomy catheter placement & $38(70.4 \%)$ & $44(68.7 \%)$ & $0.849^{b}$ \\
\hline Jj stent placement & $27(50.0 \%)$ & $33(51.5 \%)$ & $0.866^{b}$ \\
\hline Hospitalization time (hours)* & $48(24-72)$ & $72(48-96)$ & $<0.001^{a}$ \\
\hline Success & $43(79.6 \%)$ & $51(79.7 \%)$ & $0.994^{b}$ \\
\hline Hematocrit drop (\%)* & $2.0(0.9-5.8)$ & $2.3(0.2-4.8)$ & $0.370^{a}$ \\
\hline $\begin{array}{l}\text { Complications } \\
\text { Clavien dindo classification 1-2 } \\
\text { Clavien dindo classification 3-5 }\end{array}$ & $\begin{array}{c}11(20.4 \%) \\
3(5.5 \%) \\
8(14.8 \%) \\
\end{array}$ & $\begin{array}{c}19(29.7 \%) \\
13(20.3 \%) \\
6(9.4 \%) \\
\end{array}$ & $\begin{array}{l}0.247^{b} \\
0.020^{b} \\
0.363^{b}\end{array}$ \\
\hline $\begin{array}{l}\text { Clavien } 1 \\
\text { Fever } \\
\text { Pleural effusion (watchful waiting) } \\
\text { Urinary leakage (watchful waiting) }\end{array}$ & $\begin{array}{l}2(3.7 \%) \\
1(1.8 \%) \\
1(1.8 \%) \\
-\end{array}$ & $\begin{array}{l}8(12.5 \%) \\
3(4.7 \%) \\
3(4.7 \%) \\
2(3.1 \%)\end{array}$ & $0.107^{c}$ \\
\hline $\begin{array}{l}\text { Clavien } 2 \\
\quad \text { Transfusion } \\
\text { Fever requiring antibiotic replacement }\end{array}$ & $\begin{array}{c}1(1.8 \%) \\
1(1.8 \%) \\
-\end{array}$ & $\begin{array}{l}5(7.8 \%) \\
4(6.2 \%) \\
1(1.6 \%)\end{array}$ & $0.217^{\mathrm{c}}$ \\
\hline $\begin{array}{l}\text { Clavien } 3 \\
\text { Requirement for jj stent placing } \\
\text { Angioembolization } \\
\text { Thoracic tube placing }\end{array}$ & $\begin{array}{l}6(11.1 \%) \\
5(9.2 \%) \\
1(1.8 \%) \\
-\end{array}$ & $\begin{array}{l}5(7.8 \%) \\
3(4.7 \%) \\
1(1.6 \%) \\
1(1.6 \%)\end{array}$ & $0.539^{b}$ \\
\hline $\begin{array}{l}\text { Clavien } 4 \text { a } \\
\text { Acute renal failure (ICU) } \\
\text { Urosepsis }\end{array}$ & $\begin{array}{l}2(3.7 \%) \\
1(1.8 \%) \\
1(1.8 \%)\end{array}$ & $\begin{array}{l}1(1.6 \%) \\
1(1.6 \%) \\
-\end{array}$ & $0.592^{c}$ \\
\hline
\end{tabular}

Table III: Logistic regression analysis of risk factors for development of complications. 


\begin{tabular}{|c|c|c|c|}
\hline & Odds ratio & $\% 95 \mathrm{Cl}$ & p-value \\
\hline Groups (prone vs supine) & 0.538 & $0.2-1.3$ & 0.176 \\
\hline Stone size ( $\leq 25 \mathrm{~mm}$ vs $>25 \mathrm{~mm}$ ) & 2.616 & 1.1-6.4 & 0.034 \\
\hline Duration of operation ( $\leq 90 \mathrm{~min}$ vs $>90 \mathrm{~min}$ ) & 1.226 & $0.4-3.6$ & 0.708 \\
\hline CCI score( $0-1$ vs $\geq 2)$ & 2.954 & $1.2-7.3$ & 0.018 \\
\hline
\end{tabular}

Another issue is that renal stones might cause urinary tract infection, obstruction, and pain requiring analgesic intake, which deteriorates renal function in elderly patients. The miniaturisation of instruments, enabled by developments in technology (endoscopy and optic quality), means that miniPCNL under prone position can be reliably and effectively applied in the treatment of renal stones, in elderly patients according to recent reports. ${ }^{7,8}$ Supine position in PCNL provides benefits such as decreased operative time, radiation exposure, risk of circulatory and respiratory compromise, and anesthesiological advantages in the intraoperative management of such patients; despite these gains, no study has yet compared supine and prone mini-PCNL in elderly patients.

Although previous studies emphasised that PCNL causes a similar hemoglobin drop in elderly and younger patients, changes in the cardiorespiratory reserve make elderly patients more vulnerable to bleeding. Sahin et al. reported similar transfusion rates for younger and older patients, following PCNL (18\% and $21 \%$, respectively). ${ }^{9}$ Correspondingly, Iqbal et al. found no statistical difference in hemoglobin change between elderly and younger patients. ${ }^{10}$ In contrast, Resorlu et al. found that hemorrhage was a predictive factor for medical complication in elderly patients. ${ }^{11}$ In Ozgor et al., elderly patients underwent mini-PCNL, and the mean hemoglobin drop was found to be $1.1 \mathrm{~g} / \mathrm{dl}^{7}{ }^{7}$ In accordance with the literature, in the present study, mean hematocrit drop was detected $3.3 \%$ and $2.7 \%$ in supine and prone mini-PCNL group, respectively, no statistically significant difference. Transfusion rate was slightly higher in prone mini-PCNL group, which can be explained by greater occurrence of multiple punctures.

A longer operative time increases anesthesia exposure, and thus possible risks for elderly patients. An analysis by Hersey et al. showed that, in geriatric patients, prolongation in operative time was independently related to increased likelihood of postoperative thromboembolism, transfusion, urinary tract infection, and total complications. ${ }^{12}$ Previous studies have reported that age itself was not a negative factor affecting operation duration in PCNL, for example, lqbal et al. found no statistically significant difference in older and younger patients' mean operative times following PCNL. ${ }^{10}$ Falahatkar et al. reported significantly shorter operative time for the supine approach. ${ }^{13}$ In contrast the recent review of 11 studies on comparison of supine and prone PCNL by Birowo et al revealed that all reported a mean operation time, and none found a significant difference. ${ }^{14}$ Similarly, the present study reported no significant time difference between both groups, perhaps because the operation time did not include the period before the initial puncture. Using ultrasound guidance during the puncture, it has been found to decrease the period of radiation exposure. ${ }^{15}$ This was confirmed in the current study, in which fluoroscopy time was found to be significantly lower for supine mini-PCNL, due to ultrasound guidance for renal puncture.

In the literature, there is no consensus about the effect of age or patient positioning during surgery on hospitalisation stay. Okeke et al. stated that hospitalisation time after PCNL was longer in older patients. ${ }^{16}$ In contrast, lqbal et al. and Sahin et al. reported no significant difference regarding age in terms of hospitalisation time in PCNL patients. ${ }^{9,10}$ Some studies suggest that patient positioning during surgery may lead to cerebral desaturation, and that elderly patients in the prone position are more vulnerable. ${ }^{17}$ Cerebral desaturation has been associated with postoperative cognitive dysfunction and longer PACU and hospitalisation stay in studies on general surgery patients. ${ }^{18}$ In contrast, Tokatli et al. concluded that surgical position had no effect on hospitalisation stay after mini-PCNL. ${ }^{19}$ In this study, there was significantly longer hospitalisation time for prone mini-PCNL in elderly patients, perhaps due to this particular position during surgery, and significantly higher minor complication rates, all of which require management.

The effect of patient positioning in PCNL on success is controversial. Some meta-analysis in the literature finds evidence for higher success in favour of prone PCNL, ${ }^{20}$ while others find no evidence of significant difference. ${ }^{13,21}$ In previous studies, it was thought that the higher stone-free rate in prone PCNL was due to the greater mobility of the nephroscope, and the difficulty in achieving upper pole access in the supine PCNL. ${ }^{20}$ This was resolved by modifying the supine position, such as in a Galdakao modified Valdivia position, providing more space for nephroscope manipulation and a larger area for puncture, and moreover, allowed the simultaneous performance of the URS during operation, which increased the success rate. Horizontal or slightly inclined downward tract improved descending drainage and facilitated retrieval of stone fragments, and low intrapyelocaliceal pressure prevented fragment dislocation to other calices. ${ }^{21}$ Aging, another possible factor in success, has not in fact been shown to have any effect in studies. Anagnostou et al. showed no statistical difference in stone-free rates following PCNL between younger patients and elderly patients (age > 70 years). ${ }^{22}$ In a study by Hu et al. on 104 elderly patients, who underwent prone mini-PCNL, the stone-free rate in the first month was found to be $83.8 \%$. In their study, SFR were 
determined at one month postoperatively with kidneyureter-bladder radiography, ultrasonography or $\mathrm{CT}^{8}{ }^{8}$ In the current study, in contrast, for greater accuracy, the authors used abdominal CT to determine stone-free status at one month postoperatively. Acceptable stone-free rates were found in elderly patients, and results for supine and prone mini-PCNL were similar, $79.6 \%$ and $79.7 \%$, respectively.

Despite the proof of the effectiveness of the PCNL procedure, complication rates of up to $83 \%$ were reported in the literature. ${ }^{15}$ Li et al.'s recent meta-analysis of 15 studies consisting of a total of 1,474 patients, reported overall complications rates of $16.1 \%$ in the supine group and $19.2 \%$ in the prone group, i.e., no significant difference was observed. ${ }^{21}$ In the present study on elderly patients, the overall complications rate was $20.4 \%$ in supine mini-PCNL and $29.7 \%$ in prone miniPCNL. Although this difference in overall complication rate was not statistically significant, the minor complication rate was found significantly higher in the prone group. The higher incidence of urinary leakage and fever in the prone position might be associated with the inability to intervene in ureteral obstruction simultaneously, caused by stone fragments migrating to the ureter, and high intrarenal pressures during surgery. Additionally, especially in elderly patients with comorbidities, the prone position may cause problems during or after the operation, such as reduced lung compliance, risk of endotracheal tube kinking, decreased cardiac output, reduced venous return, pressure damages (breast and lip necrosis) and ischemic accidents. ${ }^{15}$ However, no cardiovascular or ischemic complication was observed in either group in this study. In the current study, two other factors were found to be predictive for complication development: stone size $>25 \mathrm{~mm}$, and $\mathrm{CCl}$ score $\geq 2$. Similarly, Turna et al. have reported that the total number of complications associated with increasing stone surface area. ${ }^{23}$ In regard to the latter, $\mathrm{CCl}$ was also to be a predictive factor in a study by Unsal et al. evaluating the efficacy of $\mathrm{CCl}$ on $\mathrm{PCNL}$ to predict of morbidity and mortality. ${ }^{24}$

This study has some limitations. The first is its retrospective design. Second, $\mathrm{CCl}$, an index designed to predict mortality using 19 comorbid conditions, was used to predict surgical complications, but not medical complications. The last limitation is the absence of long-term comparison of complications. There is a need for prospective studies with a larger series of geriatric patients.

\section{CONCLUSION}

Supine and prone mini-PCNL are equally acceptable, equally effective treatment modalities for elderly patients with renal stones. However, prone mini-PCNL had significantly longer fluoroscopy and hospitalisation time. There was no statistically significant difference in the overall complication rate, but significantly higher minor complication rate in the prone group. Stone size $>25 \mathrm{~mm}$ and $\mathrm{CCl}$ score $\geq 2$ may be considered acceptable predictive factors for higher complication rates; therefore, for older patients with high $\mathrm{CCl}$ scores, supine mini-PCNL is a potentially safer treatment method.

\section{ETHICAL APPROVAL:}

This study follows the principles of the Declaration of Helsinki; and it was approved by the Ethics Committee of the University of Health Sciences, Bozyaka Training and Research Hospital, Izmir (Meeting/Decision No. 2021/174).

\section{PATIENTS' CONSENT:}

Informed consent was not obtained due to the retrospective nature of the study design.

\section{CONFLICT OF INTEREST:}

The authors declared no conflict of interest.

\section{AUTHORS' CONTRIBUTION:}

MS: Study conception and design, analysis and interpretation of data, wrote the paper.

SY: Study conception and design, wrote the paper.

OS: Acquisition of data, critical revision.

UC: Analysis and interpretation of data, statistical analysis.

FO: Analysis and interpretation of data, critical revision.

\section{REFERENCES}

1. Türk C, Petřík A, Sarica K, Seitz C, Skolarikos A, Straub M, et al. EAU guidelines on interventional treatment for urolithiasis. Eur Urol 2016; 69(3):475-82. doi: 10.1016/j. eururo.2015.07.041

2. Chung DY, Kang DH, Cho KS, Jeong WS, Jung HD, Kwon JK, et al. Comparison of stone-free rates following shock wave lithotripsy, percutaneous nephrolithotomy, and retrograde intrarenal surgery for treatment of renal stones: A systematic review and network meta-analysis. Plos One 2019; 14(2):e211316. doi: 10.1371/journal.pone.0211316.

3. Wollin DA, Preminger GM. Percutaneous nephrolithotomy: Complications and how to deal with them. Urolithiasis 2018; 46(1):87-97. doi: 10.1007/s00240-017-1022-x.

4. Lahme S. Miniaturisation of PCNL. Urolithiasis 2018; 46(1):99-106. doi: 10.1007/s00240-017-1029-3.

5. Proietti S, Rodríguez-Socarrás ME, Eisner B, Coninck VD, Sofer M, Saitta G, et al. Supine percutaneous nephrolithotomy: Tips and tricks. Transl Androl Urol. 2019; 8(Suppl 4):381-8. doi: 10.21037/tau.2019.07.09.

6. Gokcen K, Dundar G, Bagcioglu M, Karagoz MA, Gokce G, Sarica K. Safety and efficacy of RIRS in geriatric patients: A comparative evaluation on an age based manner. Urol J 2020; 17(2):129-33. doi: 10.22037/uj.v0i0.4921

7. Ozgor F, Yanaral F, Savun M, Ozdemir H, Caglar U, Sarilar O. Comparison of miniaturized percutaneous nephrolithotomy and flexible ureterorenoscopy for moderate size renal stones in elderly patients. Kaohsiung J Med Sci 2018; 34(6):352-6. doi: 10.1016/j.kjms.2017.10.003.

8. Hu H, Lu Y, He D, Cui L, Zhang J, Zhao Z, et al. Comparison of minimally invasive percutaneous nephrolithotomy and flexible ureteroscopy for the treatment of intermediate proximal ureteral and renal stones in the elderly. Urolithiasis 2016; 44(5):427-34. doi: 
10.1007/s00240-015-0854-5.

9. Sahin A, Atsü N, Erdem E, Oner S, Bilen C, Bakkaloğlu M, et al. Percutaneous nephrolithotomy in patients aged 60 years or older. J Endourol 2001; 15(5):489-91. doi: 10. 1089/089277901750299276.

10. Iqbal N, Hasan A, Malik HA, Khan R, Nazar A, Khawaja MA. A comparison of complications and success rates after PCNL in younger and elderly patients. J Coll Physicians Surg Pak 2020; 30(12):1316-20. doi: 10.29271/jcpsp.2020.12.1316.

11. Resorlu B, Diri A, Atmaca AF, Tuygun C, Oztuna D, Bozkurt $O F$, et al. Can we avoid percutaneous nephrolithotomy in high-risk elderly patients using the Charlson comorbidity index? Urology 2012; 79(5):1042-7. doi: 10.1016/j.urology.2011.10.060.

12. Hersey AE, Durand WM, Eltorai AEM, DePasse JM, Daniels $\mathrm{AH}$. Longer operative time in elderly patients undergoing posterior lumbar fusion is independently associated with increased complication rate. Global Spine J 2019; 9(2): 179-84. doi: 10.1177/2192568218789117.

13. Falahatkar S, Moghaddam AA, Salehi M, Nikpour S, Esmaili F, Khaki N. Complete supine percutaneous nephrolithotripsy comparison with the prone standard technique. J Endourol 2008; 22(11):2513-7. doi: 10.1089/ end.2008.0463.

14. Birowo P, Tendi W, Widyahening IS, Rasyid N, Atmoko W. Supine versus prone position in percutaneous nephrolithotomy: A systematic review and meta-analysis. F1000Res 2020; 9:231. doi: 10.12688/f1000research.22940.3.

15. Cracco CM, Scoffone CM. ECIRS (endoscopic combined intrarenal surgery) in the galdakao-modified supine valdivia position: A new life for percutaneous surgery? World J Urol 2011; 29(6):821-7. doi: 10.1007/s00345011-0790-0.

16. Okeke Z, Smith AD, Labate G, D'Addessi A, Venkatesh R, Assimos D, et al. Prospective comparison of outcomes of percutaneous nephrolithotomy in elderly patients versus younger patients. J Endourol 2012; 26(8):996-1001. doi: 10.1089/end.2012.0046.

17. Deiner S, Chu I, Mahanian M, Lin HM, Hecht AC, Silverstein $\mathrm{JH}$. Prone position is associated with mild cerebral oxygen desaturation in elderly surgical patients. PLoS One 2014; 9(9):e106387. doi: 10.1371/journal. pone.0106387.

18. Ballard C, Jones E, Gauge N, Aarsland D, Nilsen OB, Saxby $B K$, et al. Optimised anaesthesia to reduce postoperative cognitive decline (POCD) in older patients undergoing elective surgery, a randomised controlled trial. PLoS One 2012; 7(6):e37410. doi: 10.1371/journal.pone.0037410.

19. Tokatli Z, Gokce MI, Süer E, Sağlam R. Supine or prone position for mini-PNL procedure: does it matter. Urolithiasis 2015; 43(3):261-4. doi: 10.1007/s00240015-0758-4.

20. Yuan D, Liu Y, Rao H, Cheng $T$, Sun Z, Wang $Y$, et al. Supine versus Prone position in percutaneous nephrolithotomy for kidney calculi: A meta-analysis. J Endourol 2016; 30(7):754-63. doi: 10.1089/end.2015.0402.

21. Li J, Gao L, Li Q, Zhang Y, Jiang Q. Supine versus prone position for percutaneous nephrolithotripsy: A meta-analysis of randomised controlled trials. Int J Surg 2019; 66:62-71. doi: 10.1016/j.ijsu.2019.04.016.

22. Anagnostou T, Thompson T, Ng CF, Moussa S, Smith G, Tolley DA. Safety and outcome of percutaneous nephrolithotomy in the elderly: Retrospective comparison to a younger patient group. J Endourol 2008; 22(9): 2139-45. doi: 10.1089/end.2007.0432.

23. Turna B, Umul M, Demiryoguran S, Altay B, Nazli O. How do increasing stone surface area and stone configuration affect overall outcome of percutaneous nephrolithotomy? J Endourol 2007; 21(1):34-43. doi: 10.1089/end.2005. 0315.

24. Unsal A, Resorlu B, Atmaca AF, Diri A, Goktug HN, Can CE, et al. Prediction of morbidity and mortality after percutaneous nephrolithotomy by using the Charlson Comorbidity Index. Urology 2012; 79(1):55-60. doi: 10.1016/j.urology.2011.06.038. 